\title{
VIVE! E LEMBRA-TE DE MIM
}

http://dx.doi.org/10.11606/issn.2237-1184.v0i34p75-90

Viviana Bosi ${ }^{\mathrm{I}}$

\section{RESUMO}

Este ensaio tem como foco principal a análise interpretativa do poema "Visitante", de Cecília Meireles, incluído no volume Vaga música (1939). Alguns traços de sua poética se delineiam nestes versos, tais como a indagação sobre possibilidade de comunicação entre o sujeito e o seu interlocutor, ou entre o poeta e seu leitor, assim como a reflexão sobre o trabalho de composição artística. O poema manifesta uma dúvida em relação ao acolhimento e à compreensão da poesia no mundo atual, referindo-se, obliquamente, a um tempo hostil ao desejo de realização de uma "vida reinventada" pela imaginação.

\section{ABSTRACT}

This paper focuses especially on the interpretative analysis of the poem "Visitante" ("The visitor"), by Cecília Meireles, included in Vaga música (1939). Some of her poetic traits are expressed in these verses, such as the questioning of the possibility of communication between the subject and his/her listener or between the poet and his/her reader. The poem also reflects upon artistic composition. It manifests a doubt in regard to the welcoming and understanding of poetry in the world today. The poem obliquely refers to a time hostile to the author's desire to accomplish a "reinvented life" through imagination.

\section{PALAVRAS-CHAVE:}

Cecília Meireles; Poesia brasileira; Sujeito lírico .

\section{KEYWORDS}

Cecília Meireles; Brazilian poetry; Lyrical subject.

I Universidade de São Paulo, São Paulo, São Paulo, Brasil. 
Conservo-te o meu sorriso para, quando me encontrares, veres que ainda tenho uns ares de aluna do paraíso...

Leva sempre a minha imagem a submissa rebeldia dos que estudam todo o dia sem chegar à aprendizagem...

Cecília Meireles. “Aluna”, Vaga música, 1942

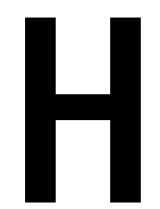

á mais de trinta anos, numa sala do curso de Letras, uma aluna ouvia a leitura de um poema que o professor de Literatura Brasileira distribuíra para a classe. Estavam todos concentrados acompanhando a voz do professor. Então, houve uma ligeira pausa na leitura, que fez a aluna levantar a cabeça da página e ver, de relance, que ele chorava. Discretamente, num átimo, a lágrima desapareceu.

Às anotações no caderno, que reproduzem de forma sumária, certamente incompleta, o que o professor dissera à época, foram se acrescentando inquietações que o poema originou ao ser relido ao longo dos anos. Assim, esta aluna se propõe a retomar, ainda que parcialmente, a análise feita em classe naquele dia e a escavar um pouco mais as evocações que o poema lhe suscitou.

A intenção é corresponder à dupla solicitação que lhe foi feita: escrever um artigo no qual exporia uma análise interpretativa adequada aos nossos cursos de graduação e, ainda, convidar aquele professor para que ele também participasse deste número especial dedicado à leitura de poesia. De modo que, estimulada pelos dois pedidos, decidiu uni-los e reformular a análise a partir das lembranças daquele dia.

Rarefeitas e esparsas serão nossas citações da fortuna crítica, tendo em vista que se trata sobretudo de uma "aula". Se mencionamos uns poucos estudos e alguns outros poemas, tudo será carreado para uma possível melhor compreensão do centro de imantação.

O poema pede leitura em voz alta: 


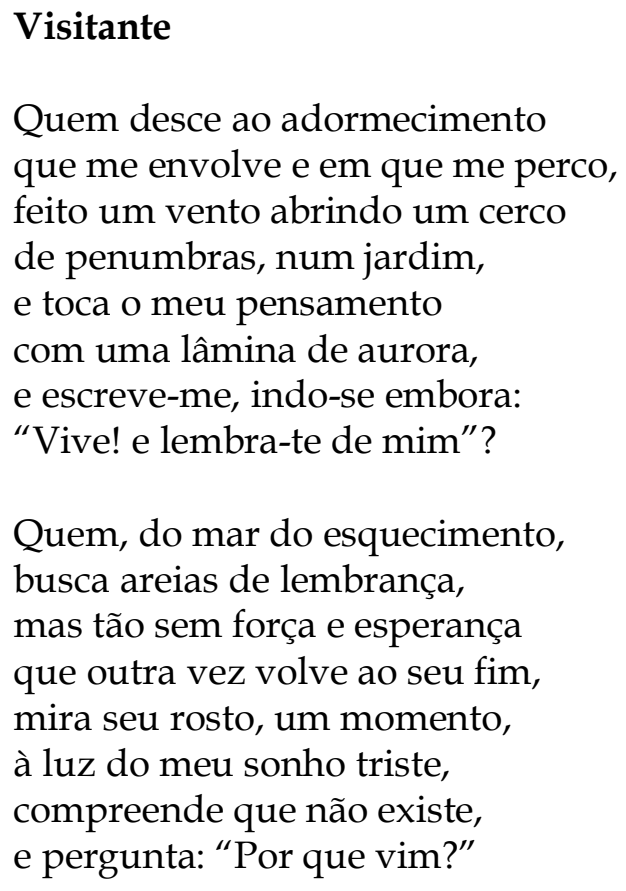

Cecília Meireles, Vaga música, 1942

Provavelmente composto durante o período da Segunda Grande Guerra, "Visitante" integra o volume considerado o segundo livro da voz madura de Cecília Meireles. Este fora precedido por Viagem (1939), livro premiado que lançara a autora para um público mais amplo, no qual já nos deparamos com características que se repropõem em grande parte de sua obra posterior. Voltaremos a isso, mas, por ora, principiemos por uma leitura mais estrita às configurações formais do poema em tela.

Nota-se bastante simetria entre a primeira e a segunda estrofes, oitavas de tradição lusitana, que se abrem com o pronome indefinido e interrogativo "Quem", uma vez que ambas terminam na forma de perguntas. Contribui com a impressão de ressonância o espelhamento engenhoso das rimas (ora paralelas ora a se repropor: ABBCADDC e AEECAFFC), assim como a métrica regular da redondilha maior. ${ }^{2} \mathrm{O}$ padrão sonoro do poema sugere que cada estrofe de oito versos poderia ser dividida em dois quartetos, já que o acento rímico enfatiza a reverberação, alternando-se as terminações ditas francesas (de palavras paroxítonas): adormecimento, pensamento, esquecimento, momento; e as chamadas rimas espanholas, consideradas mais enfáticas (palavras de acentuação oxítona): jardim, mim, fim, vim...

A pulsação rítmica marcadamente ternária e os ecos sonoros lembram os embalos da maré, quando ocorre o breve encontro que logo se

2 Com a exceção do primeiro verso, no qual tendemos a contar oito sílabas poéticas espraiamento compreensível pelo próprio sentido deste -, ou então, apertamos o compasso com uma sinérese forçada (desce-ao a) mas não impossível. Como o octossílabo é medida de verso bem comum na obra de Cecília, não surpreende esta abertura. 
esvai... Chama a atenção do leitor tantas reverberações, seja as propiciadas pelas muitas nasais, seja pela oclusiva velar $/ \mathrm{k} /$, a começar por esse "quem" conjugando ambas, que vai rebatendo para todos os lados no começo das estrofes (quem/ que me, perco, cerco, esquecimento, toca) como indagação e procura pela identidade - sujeito indefinido dessa longa primeira sentença em que um eu vai acordando, como se estivesse a se espreguiçar. De um lado, essa sonoridade mais dura do $/ \mathrm{k} /$ pode ser associada à concretude da pergunta, mas logo a sibilante /s/ ao lado da amiga dental / $\mathrm{d} /$ (desce, adormecimento), unida às nasais e à fricção suave do /v/ vêm se espraiar por todo o poema.

A repetição é ainda reiterada pela construção encadeada, paratática, em que os acréscimos coordenados parecem ondas que vão e vem. ${ }^{3}$ Cada estrofe se constitui numa grande frase, na qual as pausas do final de cada verso são sucedidas por alguns enjambements, criando uma impressão de continuidade de bloco.

O paralelismo das imagens acrescenta um tipo de balanço simétrico ao poema: na primeira estrofe, vento e aurora vêm se somar, enquanto, na segunda, mar e areia se defrontam, como se, de forma transfigurada e em uma gangorra de alternâncias, comparecessem, de modo indicial, os quatro elementos primordiais (ar, fogo, água e terra).

Um ser misterioso, que vem de cima, possivelmente de esfera superior e transcendente, irá, portanto, descer em busca do sujeito adormecido, como se este estivesse em local protegido, rodeado por um invólucro de névoa entorpecedora, no qual houvesse olvidado de si.

A princípio, apresenta-se a comparação entre $o$ visitante desconhecido e o vento que penetra um "cerco de penumbras", como se o eu lírico fosse uma bela adormecida em um jardin clos, lugar fechado e obscurecido, e o vento viesse despertá-lo com o impulso de seu sopro palavra nomeadora e espírito fecundante.

O vento estimula, aviva: ser animador que "toca com uma lâmina de aurora". Perfura e abre com ímpeto que instiga a sair desse adormecimento pelo fio agudo e luminoso a romper o ambiente recluso.

Essa epifania é, contudo, muito rápida, pois logo o visitante se retira. Insufla algum vigor, num instante que quebra a modorra, e se vai. Fica inscrito na memória pois, ao partir, deixa uma frase, um emblema: "Vive! e lembra-te de mim". Este "quem" indeterminado (criador, pneuma, amante fugaz, divindade, alter ego, memória, inspiração, inconsciente?) escreve algo fundamental. Para que o sujeito (e o próprio poema) exista, ele precisa recordar sua marca de batismo.

\footnotetext{
${ }^{3}$ Mário de Andrade, em resenha de Viagem publicada em 1939, louvava essa facilidade de Cecília Meireles para o uso das formas tradicionais, as quais proporcionavam aos seus poemas um equilíbrio entre espontaneidade e construção, proporcionando precisão expressiva.
} 
$\mathrm{O}$ visitante deixa registrada uma frase, como um mandamento, para que, a partir dela, a voz poética acorde e renasça. Ora, também nós, transformados em sujeitos pela lei da poesia, em que o eu lírico inclui o leitor, recebemos o mesmo imperativo. Assim, é estabelecido um diálogo nestes versos, em que um outro, daimon sobrenatural ou parte do inconsciente, é o responsável pela origem do sujeito. Como um Janus de duas faces, ele parece ordenar que o seu interlocutor se volte tanto para a frente quanto, em certa medida, para trás. Este " $\mathrm{e}$ " entre a primeira e a segunda frases sugere tanto um tom de coordenação quanto de adversativa. Porém, no contexto, recordar é sobretudo ser: embora a inscrição seja curta, a resistência, precária, há um reconhecimento.

$\mathrm{Na}$ segunda estrofe, o "mar do esquecimento" ecoa "adormecimento". "Esquecer" deriva do latim cadere, cair, descer, como alguém submerso que deseja aflorar. Estamos em um ambiente informe, mergulhados no líquido embrionário da indefinição onírica. O visitante poderia, desta vez, vir até de dentro do visitado. Enquanto o oceano é escuro, infinito, e nele o sujeito encontra-se praticamente fundido às águas, por oposição, alcança cristais minúsculos (as areias), grãos de ínfima, mas consistente matéria. Algo que advém das profundezas quer definir-se, através de mínimas lembranças, ao menos como vestígios de autoconsciência. A areia parece representar essa orla de esperança, metonímia da praia, quando se atinge a possibilidade de estar diante de: presença.

No entanto, como já apontamos, trata-se de um elemento próximo do pó, ao qual não se pode de fato considerar como algo consistente: as "areias de lembrança" compõem evocações escassas, quase dissolvidas.

Seria uma reminiscência subconsciente ou transcendental que tenta emergir, como um afogado a buscar a terra firme? O nascimento do sujeito e do poema poderia ocorrer agora, ao adensar-se sua figura corpórea?

Que as musas, divindades do canto, sejam filhas da memória, este poema vem corroborar, uma vez que a consciência da verdade parece coincidir com a fonte grega, na qual o inspirado, antes envolto em amnésia, quando tomado pelo entusiasmo, recebe de potências superiores $o$ desvelamento do esquecido.

Mas, tão logo desponta - cintilação passageira - o visitante volve em seguida ao seu amortecimento. Essa "outra vez" emula o movimento de uma segunda tentativa de aproximação - como uma nova onda/estrofe. Desta feita, porém, parece ter perdido a energia assertiva do sopro e da luz que o caracterizara antes. Agora é "tão sem força e esperança", que logo reflui para o "seu fim". Apareceu célere para o sujeito lírico ainda adormecido, como se este figurasse no sonho a imagem da realização do desejo em que o visitante pôde, por um instante, se enxergar refletido. 
Ora, ao "mirar seu rosto" no sonho, sugere-se a imagem do espelho, considerado, desde Platão, o próprio símbolo da mimese poética. Para o filósofo, a representação artística não continha substância concreta. Então, há uma distância entre o visitante e a realidade, como se o mundo não o pudesse acolher - o sonho de uma sombra. Já antes se insinuara o intervalo, quase intransponível, entre o plano elevado de onde proveio o ser misterioso e este lugar de oblívio e semiconsciência em que se acha o sujeito. Se o visitante veio do alto, seria ele um enviado do reino das ideias, talvez, que traria vida e ânimo ao sujeito que apenas o vislumbra, num átimo?

Outra faceta da imagem do espelho reponta frequentemente na poesia de Cecília: são numerosos os versos em que o sujeito lírico olha para o próprio rosto e não se reconhece. Sua face está perdida ou diferente do que supunha aparentar, como constatamos nesta estrofe da "Canção quase inquieta" (Vaga música):

(Mas, neste espelho, no fundo

desta fria luz marinha,

como dois baços peixes,

nadam meus olhos à minha procura...

Ando contigo - e sozinha.

Vivo longe - e acham-me aqui...)

E em outro poema, ainda:

Entre o desenho do meu rosto

e o seu reflexo,

meu sonho agoniza, perplexo.

“Epigrama do espelho infiel”, Vaga música

Em ambos, o sujeito estranha a própria face, sinédoque possível da identidade. (Perguntemos aos lacanianos o que significaria esse estágio do espelho assim fluido e impreciso).

Eventualmente se poderia considerar o visitante como uma parte de si mesmo que se desconhece? Ou seja, um estado de ânimo especial que emerge do fundo do eu para atiçar vigor na voz poética, mas não consegue se firmar e permanecer, e logo se dissipa?

\footnotetext{
${ }^{4}$ Em seu brilhante estudo da poesia de Cecilia Meireles, Leila Gouvêa (2008) desenvolve pesquisa sobre a influência da filosofia grega, especialmente de Pitágoras e Platão, ao lado da mística oriental, sobretudo no que ambas contêm de comum, como a crença na efemeridade passageira das coisas deste mundo, meras aparências, em contraposição à eternidade de uma realidade superior. Igualmente, a importância fundamental da rememoração (anamnese) para alcançar o desvendamento de verdades soterradas pelo esquecimento proveniente da reencarnação.
} 
Talvez, como na lenda de Eros e Psiquê, este forasteiro poderia ser interpretado como alma divina que vem amorosamente procurar o sujeito, na tentativa de conduzi-lo a seu reino? ${ }^{5}$ No entanto, ao descobrir que "não existe", desaponta a expectativa de elevação e de companhia do eu lírico?

Seja como for, a voz poética anseia pela chegada do visitante, que virá finalmente despertá-lo, fazê-lo viver em plenitude. Mas este, quando finalmente emerge e se manifesta, "compreende que não existe." Como o "Ulisses" de Pessoa,

\author{
Este, que aqui aportou, \\ Foi por não ser existindo. \\ Sem existir nos bastou. \\ Por não ter vindo foi vindo \\ E nos criou.
}

Mensagem, 1934

O incerto visitante, ao mirar-se à luz do sonho, se reconhece como um provável fruto da imaginação do sujeito adormecido. Como se trata de um "quem" interrogativo, poderia ser apenas um apelo íntimo da voz lírica solitária que aspira pela chegada desse alguém único, absolutamente especial, que nunca virá, a não ser no devaneio do desejo.

$\mathrm{O}$ "sonho triste" no qual o visitante, por um "momento", "mira seu rosto", evoca o isolamento do poeta moderno, que nos acompanha ao menos desde a figura do leque que desce do céu de Mallarmé: beijo proveniente do espaço que quer se aproximar, mas não encontra guarida entre os homens, como asa que não se consegue conter na mão.

De forma análoga, Mário de Andrade, ao analisar "Eco" (Viagem) no ensaio "Cecília e a poesia", escrito em 1939, se perguntava se um cão que late à noite, figura principal daquele poema, jamais acharia resposta para o sentido de sua vida, uma vez que possivelmente estava a escutar apenas o ressoar do próprio som que produzia.

O último verso contempla um desdobrar-se, quando se sobrepõem duas interrogações: enquanto o eu lírico continua a se indagar sobre quem é esse visitante, ele mesmo, de sua parte, também faz uma pergunta, seja para si mesmo seja para o sujeito seja, por fim, para o leitor: "Por que vim?". Se, na primeira estrofe desta pequena fábula, a questão partira da voz poética, nesta segunda ela foi emitida pelo seu duplo - quem sabe, ambos habitam a mesma pessoa, como instâncias divididas do sujeito. Não

\footnotetext{
${ }^{5}$ A possível reminiscência a esta lenda faz-nos lembrar do poema de Fernando Pessoa, "Eros e Psique", no qual, afinal, Eros descobre que ele e Psique são a mesma pessoa. Quem sabe aqui em nosso poema, o visitante, ao buscar acordar o sujeito lírico, também não se transforma na coisa amada, desvanecendo-se tão logo o poema seja afinal gerado?
} 
temos certeza se seriam duas personagens que se defrontam em um diálogo ou apenas um ser desdobrado.

Versos e estrofes que terminam de forma interrogativa são comuns na obra de Cecília, na qual a poeta ${ }^{6}$ é apresentada frequentemente como uma peregrina, isolada, em busca de si mesma ou de alguém impossível e ausente, que apenas no sonho poderia se revelar e, quem sabe, acolher sua sede por compreensão intensa, em um universo em que tudo é inescrutável e por vezes adverso:

Quem viu aquele que se inclinou sobre palavras trêmulas, de relevo partido e de contorno perturbado, querendo achar lá dentro o rosto que dirige os sonhos, para ver se era o seu que lhe tivessem arrancado?

"Estrela", Viagem

Quem me leva adormecida pelas dunas, pelas nuvens, com este som inesquecível do pensamento no escuro?

"Passeio", Viagem

Perguntei quem era,

Mas não respondia.

Sumiam-se as falas.

Cruzava por muros

de sombra e desgosto,

por salas e salas

de melancolia.

Perguntei: “Quem és?"

\footnotetext{
${ }^{6}$ Poeta ou poetisa? Carpeaux se insurge contra uma falsa poesia feminina, sentimental, por vezes escrita por homens, e, para distinguir Cecília Meireles deste apodo "pejorativo", prefere chamála de "poeta" (1999: 874). Também por isso, apesar da argumentação extraordinariamente bem articulada de Maria Lúcia Dal Farra (2006), que nos inclinaria a empregar sem medo o temo "poetisa", vamos continuar a utilizar "poeta", esta palavra hoje considerada de gênero uniforme. O estudo desenvolvido por Dal Farra perscruta a obra de Cecília Meireles como um todo, ao deter-se em temas centrais (como a importância do espelho, do nome, do corpo, da transitoriedade, e em tantos outros), à volta do que seria a defesa do feminino numa poesia reputada como universalista e praticamente andrógina. Assim, convenceu-nos em relação ao reconhecimento inequívoco da porção mulher nas imagens que ela convoca. (Recomendamos fortemente a leitura do ensaio de Dal Farra, poeta e poetisa que vai a fundo em sua reflexão sobre Cecília Meireles). Mas, por não querer de forma alguma diminuir essa grande poesia com os preconceitos existentes à volta de um termo estigmatizado, permanecemos, por ora, empregado a definição mais consensual. Heloísa Buarque de Hollanda organizou uma antologia de poesia contemporânea escrita por mulheres à qual deu o título de As 29 poetas hoje (2021). A diferença entre o estilo de Cecília e a poesia feminina atual não poderia ser mais estridente, o que (quase) nos tenta a chamá-la de poetisa, por contraste...
} 


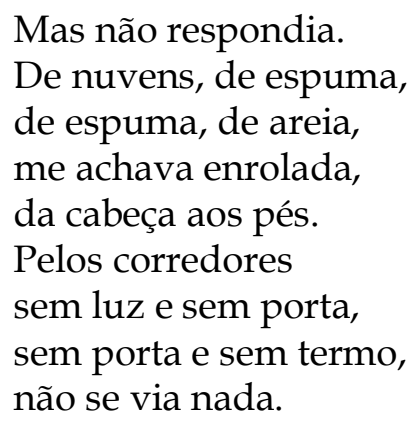

"Alucinação", Vaga música

Enquanto todos os verbos estão no presente em "Visitante" (pois desenrola-se um aqui e agora instantâneo, característico da recordação lírica), a pergunta "Por que vim?" já acontece no passado, a evidenciar o fim da visita e do poema. Na primeira parte, os verbos denotam atividade, ao passo que os últimos, em sua maioria, tendem à introspecção (mirar, compreender, perguntar). Esta indagação final parece resultar de um indício súbito de consciência (em meio ao sonho) decorrente do ato de refletir-se: o visitante, ao reconhecer o próprio rosto-poema, conclui tanto pela sua inutilidade quanto pela sua inexistência no mundo real. Sua tentativa de encarnar-se perdeu o sentido no momento mesmo do encerramento do poema. O trajeto esgotou-se ali mesmo, como se ele admitisse a própria insignificância para quem o poderia tê-lo recebido. Perfeito, dissolveu-se, incompreendido e ignoto.

É acentuada a discrepância entre o tom exclamativo da primeira afirmação do visitante, que se dirige certeiro ao seu interlocutor, no imperativo, e sua segunda fala, dubitativa e encolhida no sonho, desconfiada até mesmo da própria realidade.

Ressoa, neste passo, a reflexão de Agamben sobre o fim do poema o momento em que, reunidos o sentido completo e os ecos sonoros, ambas as correntes, semântica e a semiótica, confluem para o ponto em que se "destruiria a máquina poética, precipitando-a no silêncio", pois "o que resta do poema depois da sua ruína?" (2002, p. 146-7). E ainda, o que resta do sujeito lírico na modernidade, agora confinado ao espaço da intimidade e da imaginação?

Pois, afinal, quem poderia ser o visitante?

Um deus momentâneo que quer se manifestar? um sentimento do transcendente que sobrevive nesse mar infinito e inexplicável do inconsciente? ou uma inspiração que aspira a materializar-se em palavras escritas? seria a expressão do poético que não encontra lugar no mundo real, apenas no imaginário, no sonho que é triste porque não pode realizarse, não tem lugar ou sentido e logo recua para o nada? ou, quem sabe, o anseio pela companhia do Eleito para o sujeito lírico, solitário como a 
harpista na estação de águas? ou, por fim, o instinto vital do poeta a irromper por um instante em meio à sua infindável melancolia?

Esse "quem", ao que se pode inferir, parece ser uma voz que tenta entender o sentido do trajeto vital ao buscar o poeta no poema, todavia a já se despedir no último verso. Teria essa rápida existência entre duas águas nos alcançado antes de refluir? “O Tu, em última instância, é enigma, porque a sua perenidade na memória corresponde à sua transitoriedade no tempo", por isso, "A construção da presença é uma alegria difícil porque fundada na dor da ausência", percebe Alfredo Bosi (2003, p. 126).

Haveria, no fundo, talvez, certo tom elegíaco de reminiscência biográfica, tendo em vista seja o perecimento precoce de tantos membros da família de Cecília e, ainda recente, a morte trágica do primeiro marido? Miguel Sanches Neto descreveu esta poesia como de "lirismo orfânico" (2001, p. xxiii), dado o alto número de perdas que a autora sofreu. Nesse caso, o visitante se reportaria a um ser amado, infelizmente transitório, que intentaria insuflar alento vital no sujeito lírico, antes de dissolver-se como miragem fantasiosa. O âmago existencial de tanta dor possivelmente se converteu em sublimação artística. Fios de melancolia, no sentido de saudade de um objeto ideal perdido, irradiam-se por esta poética, como "gritos transfigurados".

Em versos nos quais Cecília se refere à família pregressa, tão longínqua que sua existência parece até fruto da imaginação, os antepassados mortos a exortam:

\author{
Vive! - clamam os que se foram, \\ ou cedo ou irrealizados. \\ Vive por nós! - murmuram suplicantes. \\ "Compromisso", Mar absoluto, 1945

Especular sobre quem fala, de onde fala, ou de que tipo são as vozes líricas, é questão em aberto, especialmente na poesia moderna. Pressupõese que o sujeito lírico vá se constituindo através da criação do poema, entre a matéria biográfica e o trabalho de composição.

Assim, João Cabral, para exemplo de contraste com Cecília Meireles, apresenta seu eu poético em construção, numa fala da personagem Raimundo em "Os três mal-amados" (1943):

Maria era também a folha em branco, barreira oposta ao rio impreciso que corre em regiões de alguma parte de nós mesmos. Nessa folha eu construirei um objeto sólido que depois imitarei, o qual depois me definirá. Penso para escolher: um poema, um 
desenho, um cimento armado - presenças precisas e inalteráveis, opostas à minha fuga. (MELO NETO, 1995, p. 63) 7

É como se, de propósito, Cabral resolvesse dela diferir em tudo em seu programa estético. Nada mais distante da "graça aérea" de Cecília Meireles (com bem definiu-a Bandeira, 1997, p. 452). Sem dúvida, se esta poesia tende a ser tanto musical quanto pictórica, suas imagens e mesmo sua sonoridade costumam ser mais suaves do que as cabralinas. Uma vez que a voz lírica se define como "pastora de nuvens", Sanches ressalta "o inefável e fugidio", o "viver em suspensão", "o elemento móvel, mutável, inapreensível", em que ela se contrapõe aos "pastores da terra", que creem em firmeza e limites: "Nuvens versus pedras. O informe em permanente mutação versus a matéria repousada em sua forma eterna", pois "Um está fixado a um espaço e faz dele a sua identidade. O outro leva uma existência imprecisa." (SANCHES, 2001, p. xxiv-vi). O próprio título do volume em que se localiza "Visitante" remete a essa melodia indefinida e nebulosa: Vaga música. Embora, na obra de Cecília, as imagens sejam delineadas com clareza e precisão, o encontro epifânico supõe um contato algo ligeiro: "Coisa que passas, como é teu nome?", diz um verso emblemático, - quase como se a poeta quisesse alcançar um objeto que se dissipa antes que ela pudesse apreendê-lo. Em "Descrição" (Viagem, 1939), Cecília se refere a uma água que reflete as estrelas, as folhas, o céu, mas quando nela se mergulha a mão, o contorno das coisas refletidas se desvanece. A água flui e desliza sem que se possa apanhar coisa alguma. Apesar da desolação que acompanha o gesto, algo permanece, pois resta "um esplendor sobre a sua passagem" e uma "inútil beleza/ nessas mãos que desenham dentro da água sua viagem/ para fora da natureza", mesmo que nunca se possa extrair nada de sólido desse elemento líquido. A poeta, ainda assim, continua sua atividade, como um "peixe bebendo o mar", tentando abraçar o céu, as estrelas, as folhas espelhadas, para tentar segurá-las transformando-as em palavras, enquanto tudo prossegue em seu devir fugidio de "Inscrição na areia". Como bem formulou Leila Gouvêa, haveria, na obra de Cecília, uma tendência dominante ao "heraclitiano fluxo permanente e irreversível do tempo e das coisas" (2008, p. 34).

Quando se afirma que ela era moderna sem ser modernista, em parte está se referindo a isto: de um lado, tanto o manejo de formas tradicionais de composição quanto a utilização de imagens aparentadas com o lirismo simbolista (flor, estrela, mar, pássaro...); de outro, a percepção da profunda solidão causada pelo desajustamento em relação aos demais seres humanos, acentuada ainda pela consciência do hiato entre a vida

\footnotetext{
7 Há pequenas diferenças na escolha do vocabulário entre a edição original de "Os três malamados" e esta que consta do volume revisto por Cabral em sua Obra completa, da qual extraí a citação. São algumas substituições por sinônimos que não alteram substancialmente o sentido.
} 
presente e o sonho, sobre o qual o poema intenta saltar, lançando-se como visitante imaginário. Outro traço de sua modernidade "kantiana", por assim dizer, afirma-se na atitude "desinteressada e efêmera" da sua canção, cujo maior propósito é ser "flor do espírito", sem utilidade a não ser tornar "o mundo mais belo". Canto no deserto, sem saber se alguém o escutará.

Essa lucidez sobre o exílio do poeta é reconhecida como infelicidade em vários títulos de Viagem (1939), livro imediatamente anterior a Vaga música, os quais se referem à orfandade, ao desamparo, à renúncia. Dentre eles, distinguimos "Estirpe", em que a voz lírica se identifica com os mendigos mais desprovidos de tudo - aqueles que já nem pedem nada, excluídos do convívio humano. Como aventamos, quem sabe o visitante não representaria a própria poesia sem lugar, apenas visível à luz do sonho? Mas, ela não desiste de se interrogar sobre a sua possibilidade de habitar este mundo, ou mesmo, de indagar se de fato existe para o seu interlocutor, uma vez que sua vinda a ninguém interessa. Ainda que a tentativa de acordar o leitor adormecido seja vã, o poema insiste até sua (quase) derrota.

Em busca deste horizonte utópico, incessantes imagens de caminhada, viagem e navegação se repropõem em sua obra, por vezes terminadas em naufrágios e outros insucessos. Acontece de as andanças ocorrerem durante o sonho, quando mesmo a esperança do diálogo com esse ente ideal parece improvável:

Procurei-te em vão pela terra, perto do céu, por sobre o mar. Se não chegas nem pelo sonho, por que insisto em te imaginar?

$$
\text { de "Canção quase melancólica", Vaga música }
$$

Ai! por mais que se ande, é certo:

- não se encontra o bem perfeito.

Vai nascendo só deserto

pelo peito.

E entre o desejado e o aceito

dorme um horizonte encoberto.

\section{"História", Viagem}

A paisagem percorrida pela poeta nestas deambulações é, sobretudo, mental e imaginária, assim como a sua temporalidade. Os herdeiros do simbolismo, dentre os quais a crítica coloca, com razão, Cecília Meireles, habitam esse "cronotopo" de aparência intemporal (na expressão de CARPEAUX, 1999), e tendem a se valer de figurações extraídas da natureza para dar corpo aos cenários do devaneio poético. A ausência de 
factualidade propriamente cotidiana e histórica em época tão brutal deve corresponder a alguma razão fundada. Em "Visitante", isso se explicita, em nosso parecer, quando o sujeito descreve seu sonho como "triste" provavelmente porque ele reconhece que não pode realizar-se na vida.

Leila Gouvêa comenta as múltiplas vezes em que a poeta retoma o tema da inutilidade da poesia em um tempo de barbárie, no qual sua aspiração seria viajar para uma realidade transfigurada. Para o "pássaro da lua" que quer cantar, este é um período completamente desfavorável, no qual ele não tem como pousar em parte alguma. Sua procura por acolhimento é baldada pois ninguém conseguirá sequer escutá-lo. O sujeito lírico reconhece que agora as cigarras não têm vez, pois um "sopro de fim de mundo" amedronta a todos.

Os críticos são unânimes em afirmar certo tom nostálgico, como quem paira acima da temporalidade presente, proclamando, por suas imagens de nuvens e águas, um ideal de transitoriedade permanente. Sanches observa que, na sua "condição de andarilha solitária", a poeta encontra apenas no canto o seu espaço de vida plena, como quem caminha em direção a longínquos horizontes mas, ressalva: “Cecilia Meireles não pode ser entendida como representante da estética torre de marfim, que permanece indiferente aos acontecimentos. As suas conhecidas atividades pedagógicas e jornalísticas desfazem a imagem de uma pessoa isolada numa individualidade cavilosa." (2001, p. xliv). São vários os trechos de poemas e crônicas que aludem à guerra, como se reconhece especialmente em Mar absoluto (1945).

De Vaga música, livro que ora destacamos, identificam-se referências diretas:

Amanheceu pela terra um vento de estranha sombra, que a tudo declarou guerra.

Paredes ficaram tortas, animais enlouqueceram e as plantas caíram mortas.

“Descrição"

No estrondo das guerras, que valem meus pulsos? No mundo em desordem, meu corpo que adianta? A quem fazem falta, nos campos convulsos, meus olhos que pensam, meu lábio que canta?

\section{"Partida"}

Intitulando-se paradoxalmente como "SERENA DESESPERADA", seu maior intento é ser apenas "essa que sofreu de beleza/ e nunca desejou 
mais nada." ("Epitáfio da navegadora", Vaga música). Busca sem cessar outra terra, um povo que não há: "Porque a vida, a vida, a vida,/ a vida só é possível/ reinventada." ("Reinvenção", Vaga música). Partir para longe quando se desconfia que o lugar almejado sequer existe... Cito Leila Gouvêa: "o sujeito poético bate, também recorrentemente, com a inviabilidade da transcendência e imerge na dúvida - a qual, tanto quanto a procura do Absoluto, atravessa toda sua lírica." (2008, p. 98). O visitante, representando a intuição de um mundo superior, inclina-se sobre o sujeito poético para despertar seu espírito para uma vida mais intensa, e, ao mesmo tempo, não pode de fato fixar-se na realidade: duplo movimento, central para a compreensão desta poética.

Se mágoa, sombra e solidão avultam em tantos versos amargos, este não é o único tom de obra tão complexa. Há momentos de remanso e serenidade, há até alguma alegria, ainda que rara. Seu canto por vezes busca infiltrar-se no horizonte escuro, como um broto trazendo a primavera para um solo de areia e de gelo ("Epitáfio da navegadora", Vaga música) ou como "finos deltas de felicidade/ abrindo os braços num oceano triste" ("Mar em redor", Vaga música). No entanto, a felicidade é precária e veloz, assim como o encontro, num átimo, com este momento de enlevo proporcionado pelo visitante inspirador.

No elemento líquido e movente do sonho, em que o mar representa a inconstância enquanto a estrela parece traduzir o anseio por luminosidade e certeza, o poema é seu salvo-conduto, o seu barco em que rema ritmada. Mesmo que "como que pra ninguém", a canção a mantém, por efêmeros instantes, resguardada e livre (libérrima...).

A pergunta final do nosso poema, sobre o sentido da visita, pode dar a impressão da ineficácia desse fantasma. Por que vim, porque vim, porque vim? é a frustrante indagação do poema, semelhante à do professor lendo poesia na sala de aula e a do estudante sendo despertado por essa voz. Una furtiva lagrima... Quantas vezes fomos ora professores ora alunos e nos identificamos com essa sensação que nos desdobra entre visitante e visitado?

Como os poetas que já cantaram,
e que já ninguém mais escuta,
eu sou também a sombra vaga
de alguma interminável música!

Pára em meu coração deserto!

Deixa que te ame, ó alheia, ó esquiva...

Sobre a torrente do universo, nas pontes frágeis da poesia. lagartixa!

é o apelo de "Comunicação" (Retrato natural, 1949) a uma... 
No entanto, o poema se fez e nadou até a nossa praia. Nós o miramos em nosso sonho. Então, talvez, Cecília Meireles estivesse se perguntando de onde vem e como se constitui esse ente misterioso que com tanta dificuldade e insegurança, em um mundo surdo e indiferente, tenta descobrir quem o receba para se fazer poema.

Não deixa de ser a própria contradição performativa que se exprime neste visitante, uma vez que sendo um, ou dois, ou ninguém, ele gerou vida e poesia, enquanto durou, no sujeito antes inerte. "Like a wave breaking on a rock, giving up/ Its shape in a gesture which expresses that shape." (John Ashbery, "Self-portrait in a convex mirror, 1975).

Se dele nos lembramos, a última indagação, "Por que vim?", poderia, quem sabe, obter uma resposta, assegurada que foi não apenas a existência do poeta e do poema, mas seu eco infindo de onda sempre retomada. $\mathrm{O}$ acolhimento foi tênue e logo se esvaiu, mas, ao menos por um instante fugaz, ocorreu o encontro sensível entre aquele eu adormecido e esse vento e essa lâmina aguda que traz aurora, toca o pensamento e nele inscreve a geração do sujeito lírico no poema, que nos visita por poucos segundos antes de desvanecer-se e, como a fênix, renasce, asa ritmada.

\section{Referências bibliográficas}

AgAmbEN, Giorgio. "O fim do poema”. Tradução de Sérgio Alcides. Cacto. Santo André, n. 1, p. 142-9, ago. 2002.

ANDRADE, Mario de. “Cecília e a poesia”. In: O empalhador de passarinho. São Paulo: Martins Fontes, 1955, p. 71-5.

ANDRADE, Mario de. "Viagem". In: O empalhador de passarinho. São Paulo: Martins Fontes, 1955, p. 161-4.

BANDEIRA, Manuel. “Estudos literários". In: Seleta de prosa. Rio de Janeiro: Nova Fronteira, 1997, p. 361-532.

Bosi, Alfredo. “Em torno da poesia de Cecília Meireles". In: Céu, inferno. São Paulo: Duas Cidades: 34, 2003, p. 123-44.

CARPEAuX, Otto Maria. "Poesia intemporal". In: Ensaios reunidos. vol. I. Rio de Janeiro: Topbooks: UniverCidade, 1999, p. 873-6.

DAL FARRA, Maria Lúcia. “Cecília Meireles: imagens femininas”. Cadernos Pagu. Campinas, n. 27, p. 333-71, jul-dez. 2006.

GOUVÊA, Leila Vilas-Boas. Pensamento e "lirismo puro" na poesia de Cecília Meireles. São Paulo: Edusp, 2008.

MEIRELES, Cecilia. Poesia completa. vols. I e II. Organização de A. C. Secchin. Rio de Janeiro: Nova Fronteira, 2001. 
MELO NeTO, João Cabral. “Os três mal-amados”. In: Obra completa. Rio de Janeiro: Nova Aguilar, 1995, p. 57-64.

SANCHES NeTO, Miguel. "Cecília Meireles e o tempo inteiriço". In: MEIRELES, Cecilia. Poesia completa, vol. I. Organização de A. C. Secchin. Rio de Janeiro: Nova Fronteira, 2001, p. xxi-lix.

Recebido em 19 de março de 2021

Aprovado em 19 de outubro de 2021

Viviana Bosi é professora livre-docente do Departamento de Teoria Literária e Literatura Comparada da Universidade de São Paulo. Publicou, este ano, o livro Poesia em risco. Itinerários para aportar nos anos 1970 e além (2021). Escreveu o livro John Ashbery, um módulo para o vento (1999). Organizou o livro Antigos e soltos (2008), com textos na maior parte inéditos de Ana Cristina Cesar. Co-editou os livros coletivos Sereia de papel: visões de Ana Cristina Cesar (2015) e Neste instante: novos olhares sobre a poesia brasileira dos anos 1970 (2018), dentre outros trabalhos. Contato: vivianab@usp.br

ORCiD: https://orcid.org/0000-0002-0217-494X. 